\title{
Synthesis, Characterisation and Antimicrobial Study of Cobalt (II) Complex of a Schiff Base Derived from Isonicotinic acid Hydrazide and 4-Chlorobenzaldehyde
}

\author{
Kumble Divya*, Gayathri B. H \\ Assistant Professor, Post Graduate Department of Chemistry, B.M.S College for women, Basavanagudi, Bengaluru, Karnataka, India. \\ *Corresponding author's E-mail: kumbledivya71088@gmail.com
}

Received: 21-08-2020; Revised: 16-10-2020; Accepted: 28-10-2020; Published on: 15-11-2020.

\section{ABSTRACT}

New Schiff base ligand N'-[(4-chlorophenyl) methylidene] pyridine-4-carbohydrazide has been synthesized and complexed to Co(II) metal ion. The Schiff base ligand was synthesized by the condensation of Isonicotinoyl hydrazone with 4-chlorobenzaldehyde. The ligand and their metal complex is characterized by $\mathrm{C}, \mathrm{H}, \mathrm{N}$ analysis, IR spectra and UV-Vis for tentative structure proposal. The ligand is coordinated to Co(II) metal ion through the enolic oxygen and azomethine nitrogen resulting in a square planar geometry. The ligand and metal complex were studied for their antimicrobial activities against gram positive and gram-negative bacteria. The metal complex shows more potent activities compared with Schiff base ligand.

Keywords: Schiff Base, Metal - organic frame work, IR spectra, UV-Visible, Antimicrobial.

QUICK RESPONSE CODE $\rightarrow$

DOI:

10.47583/ijpsrr.2020.v65i01.011

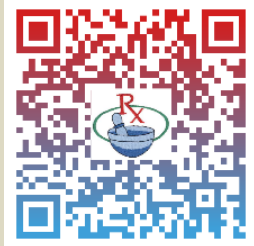

DOI link: http://dx.doi.org/10.47583/ijpsrr.2020.v65i01.011

\section{INTRODUCTION}

S ynthesis of metal complexes attained increasing interest owing to their versatile coordination behaviour and in the understanding of molecular processes $^{1}$. Metal complexes are of significant attention in terms of its structural and coordination chemistry. They display diverse chemical, optical and magnetic properties by tailoring with different ligands. In specific, the study of metal complexes of Schiff base (SB) ligands appears to be fascinating in terms of unusual structure and stability ${ }^{2}$. SB complexes are considered to be among the most important stereo chemical models in transition metal coordination chemistry due to their preparative accessibility, structural variability ${ }^{3,4}$. SB are condensation product of primary amines and carbonyl compounds. SB is an analogue of a ketone/ aldehyde in which the carbonyl group has been replaced by an azomethine group. SB are important intermediates for the synthesis of various bioactive compounds 5 . They show a variety of biological activities including antibacterial, antifungal, anti-cancer etc. Schiff base is an important intermediate in many enzymatic reactions ${ }^{6}$.

Recently a great deal of interest have been developed in the synthesis and characterization of transition metal complexes containing SB as ligands due to their variety of applications in biological, clinical, analytical and industrial fields ${ }^{7}$. Among these, SB ligands and their metal complexes do have significant interest because of their pharmacological activities ${ }^{8}$. Furthermore, the enhanced biological activity of these complexes has extended much attention due to their possible applications as new therapeutic agents ${ }^{9}$. SB derived from an amino and carbonyl compound are an important class of ligands that coordinate to metal ions via azomethine nitrogen ${ }^{10}$. It was found in the literature that presence of $\mathrm{C}, \mathrm{N}$ linkage in azomethine derivatives, was responsible for remarkable antibacterial, antifungal, anticancer and antimalarial activities $^{11}$.

Isonicotinoyl hydrazide (INH) is a first reported antituberculosis drug ${ }^{12}$, synthesized from isonicotinic acid which is produced from 4- methylpyridine ${ }^{13}$. Hydrazide moiety present in the molecule of $\mathrm{INH}$ can readily undergo SB condensation with compounds containing carbonyl function to form their corresponding hydrazones. Literature survey documented for high bactericide and fungicide properties of INH based SB ${ }^{14}$.

Thus, in the present work INH based SB is synthesized and complexed with cobalt. The coordination chemistry of cobalt has a considerable interest since cobalt complexes derived from $S B$ are reported to be biologically active ${ }^{15}$. The cobalt SB complexes are also an important class of coordination compounds, not only because of their involvement in Vitamin $B_{12}$ models and oxygen carrier properties, but also due to their interesting magnetic and spectroscopic as well as diverse binding ability ${ }^{16}$. A large number of reports on the antibacterial properties of cobalt complexes reported in the literature, presumably due to their aqueous stability, availability, and ease of synthesis ${ }^{17}$.

Keeping the above facts in mind in our present work we have chosen to synthesize SB derived from INH and 4chlorobenzaldehyde followed by its complexation with Co(II) metal. The ligand and its metal complexes were also screened for in vitro antibacterial activity against Staphylococcus aureus and Escherichia coli. Studies show 
that the metal complexes of SB ligand have better antimicrobial activities as compared to SB.

\section{MATERIALS AND METHODS}

All the reagents were used namely INH, 4chlorobenzaldehyde, cobalt chloride, ethanol are of synthetic grade.

Elemental microanalysis of the compounds, C, H and $\mathrm{N}$ were performed using Shimadzu elemental vario EL III model elemental analyser. Melting points of the ligand and its complexes were recorded on an OMEGA melting point apparatus. The $\mathrm{pH}$ measurement was done on the Elico-16 $\mathrm{pH}$ meter. The IR spectra were obtained in a $\mathrm{KBr}$ disk using a BIO-RAD FTS 135 spectrometer, the UV-VIS spectra were recorded in PC based double beam spectrophotometer 2202 in N,N'-dimethylformamide (DMF) solution.

\section{Synthesis of schiff base}

The SB (ligand) was prepared by mixing a warm dilute ethanoic solution of INH $(0.01 \mathrm{M})$ with ethanoic solution of 4-chlorobenzaldehyde (0.01M) under reflux for 4-5 hours in a water bath. The clear solution was poured into cold water $(500 \mathrm{ml})$ and the solid precipitated was then filtered, washed with cold water, dried and then recrystallized. The prepared compounds were checked for purity by TLC using glass plates percolated with silica gel 60 GF254 and suitable solvent system as mobile phase.

\section{Synthesis of metal complex}

The SB was taken in alcohol $\left(0.02 \mathrm{M}, 50 \mathrm{~cm}^{3}\right)$ and stirred gently for one hour to give a homogeneous solution and then mixed with alcoholic solution of metal salt i.e., Cobalt (II) chloride $\left(0.01 \mathrm{M}, 25 \mathrm{~cm}^{3}\right)$. The resulting solution was refluxed for 6-8 hrs. The mixture was concentrated to half of its initial volume and kept in a desiccator for two days over anhydrous $\mathrm{CaCl}_{2}$. The complex was then filtered, washed with ethanol and dried. The complex was soluble in DMF but sparingly soluble in other common organic solvents and water.

\section{Biological assay: preparation of nutrient broth}

Nutrient broth gel was prepared to study antimicrobial activity of the synthesised compounds. Different concentrations of metal complex in a test tube $(0.05,0.1$, $0.15,0.2$, and $0.25 \mathrm{M}$ ) were taken for gram positive and gram negative bacteria respectively. Nutrient broth gel was added to each test tube and covered with cotton plug. The solution is then kept in an autoclave about an hour and after autoclaving it is cooled at room temperature. By using Broth Dilution Method it was tested for gram positive bacteria Staphylococcus aureus and gram negative bacteria Escherichia coli. Added two drops of SB solution and complex solution to each test tube using pipette and stirred well before keeping it in BOD incubator. After 24 hours microbial growth was examined by comparing it with the control solution. Both showed positive results.

\section{RESULTS AND DISCUSSION}

\section{Physical measurements}

The physical properties and the microanalytical data of the ligand and metal complexes are summarized in the Table 1. The analytical results show (1:2) metal ligand ratio, i.e., $\mathrm{ML}_{2}$ type. The colour change from ligand to metal complexes is in support of metal ligand interaction which is further reinforced by conductivity and $\mathrm{pH}$ measurements. The ligand is soluble in ethanol. The complex is soluble in DMF. Molecular formulae of the ligand and metal are proposed based on the results of microanalytical tool in combination with spectral techniques. The experimental molar conductivity data of metal complexes is found in the range of $6.6-33.2 \mu \mathrm{S} / \mathrm{cm}$ which suggests their nonelectrolytic nature of the complex. The $\mathrm{pH}$ of ligand and complexes was almost in the neutral range.

Table 1: Physical data of the synthesised compound

\begin{tabular}{|c|c|c|c|c|c|c|c|c|}
\hline \multirow[t]{2}{*}{ Compound } & \multirow[t]{2}{*}{ Formula } & \multirow[t]{2}{*}{ Colour } & \multirow[t]{2}{*}{ M.P $\left({ }^{\circ} \mathrm{c}\right)$} & \multirow[t]{2}{*}{ Yield \% } & \multicolumn{3}{|c|}{ Cal(found) \% } & \multirow[t]{2}{*}{$\mathrm{UV}\left(\lambda_{\max }\right)(\mathrm{nm})$} \\
\hline & & & & & C & $\mathbf{H}$ & $\mathbf{N}$ & \\
\hline $\mathrm{L}=($ Schiff base ) & $\mathrm{C}_{14} \mathrm{H}_{13} \mathrm{~N}_{3} \mathrm{O}_{2} \mathrm{Cl}$ & Off white & $208-212$ & 78 & $\begin{array}{c}60.12 \\
(60.02)\end{array}$ & $\begin{array}{c}3.88 \\
(3.98)\end{array}$ & $\begin{array}{c}16.18 \\
(16.01)\end{array}$ & 410 \\
\hline$\left[\mathrm{Co}(\mathrm{L}) \mathrm{Cl}_{2} \mathrm{H}_{2} \mathrm{O}\right.$ & $\begin{array}{c}{\left[\mathrm{Co}\left(\mathrm{C}_{56} \mathrm{H}_{52} \mathrm{~N}_{12} \mathrm{O}\right]\right.} \\
\mathrm{Cl}_{2} \cdot \mathrm{H}_{2} \mathrm{O}\end{array}$ & Dark brown & $320-330$ & 80 & $\begin{array}{c}60.16 \\
(60.24)\end{array}$ & $\begin{array}{c}3.78 \\
(3.88)\end{array}$ & $\begin{array}{c}16.15 \\
(16.13)\end{array}$ & 540 \\
\hline
\end{tabular}

\section{Chemistry and electronic spectra}

The condensation reaction of INH and 4chlorobenzaldehyde under reflux conditions results in the formation of the SB ligand namely N'-[(4-chlorophenyl) methylidene] pyridine-4-carbohydrazide. The ligand is subsequently reacted with chloride salts of Co(II) to give corresponding metal complex. The proposed synthetic route of the ligand and the Co(II) complexes are given in Scheme 1.
The ligand and metal complexes are of different colours, the ligand is off-white while the complexes of $\mathrm{Co}$ (II) are dark brown in colour. The ligand is soluble in ethanol while the metal complex is only soluble in DMF. The SB melted at $208-212^{\circ} \mathrm{C}$ and the complex have melting point above $320^{\circ} \mathrm{C}$. The structures of the products are confirmed by the elemental analysis, which shows that the difference between the found values and calculated values of carbon, hydrogen and nitrogen elements are situated within the range which confirms the correctness of the suggested structures of the prepared compounds. The Schiff base 
ligand shows absorption band at $410 \mathrm{~nm}$ is assigned to $\mathrm{n}$ $\pi^{*}$ transition. On complexation the absorption band was shifted to $540 \mathrm{~nm}$ (Figure 2a) due to the formation of coloured complex.

\section{Stoichiometry of the reaction product}

Complex obtained is studied in DMF solution to determine the $\mathrm{M} / \mathrm{L}$ ratio in the complex by Job's Method ${ }^{18}$. A series of solutions were prepared with a constant concentration $\left(10^{-3} \mathrm{M}\right)$ of the metal ion and ligand, SB. The $\mathrm{M} / \mathrm{L}$ ratio was determined from the relationship between the absorption of the absorbed light and the mole ratio of $\mathrm{M} / \mathrm{L}$. The study shows that the metal to ligand, ratio was $1: 2$. In view of this result, a reaction mechanism is proposed and metal to ligand ratio is to be considered as 1:2.

\section{Overall scheme}<smiles>NNC(=O)c1ccncc1</smiles>

Isoniazide<smiles>O=Cc1ccc(Cl)cc1</smiles>
4-chlorobenzaldehyde<smiles>O=C(N/N=C/c1ccc(Cl)cc1)c1ccncc1</smiles>

$N^{\prime}-[(E)$-(4-chlorophenyl)methylidene]pyridine-4-carbohydrazide

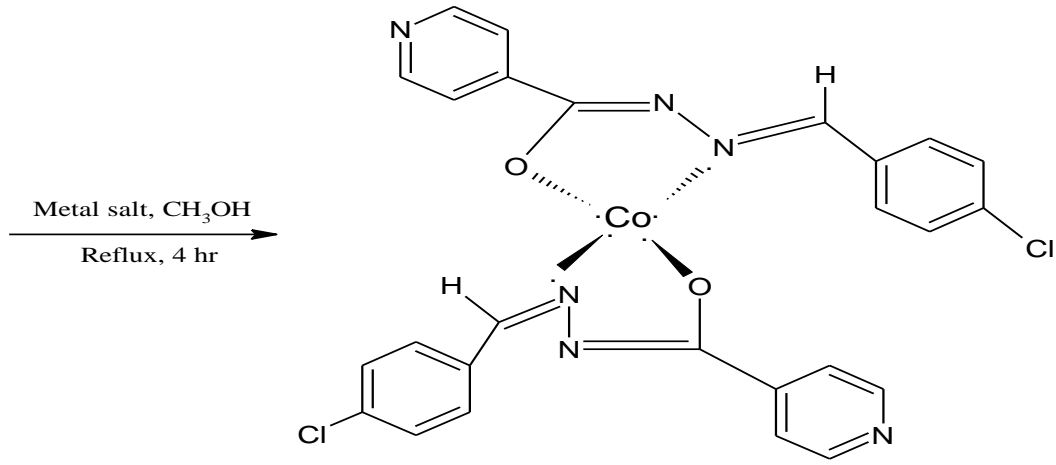

Scheme 1: Reaction of INH with 4-chlorobenzaldehyde followed by the complex formation

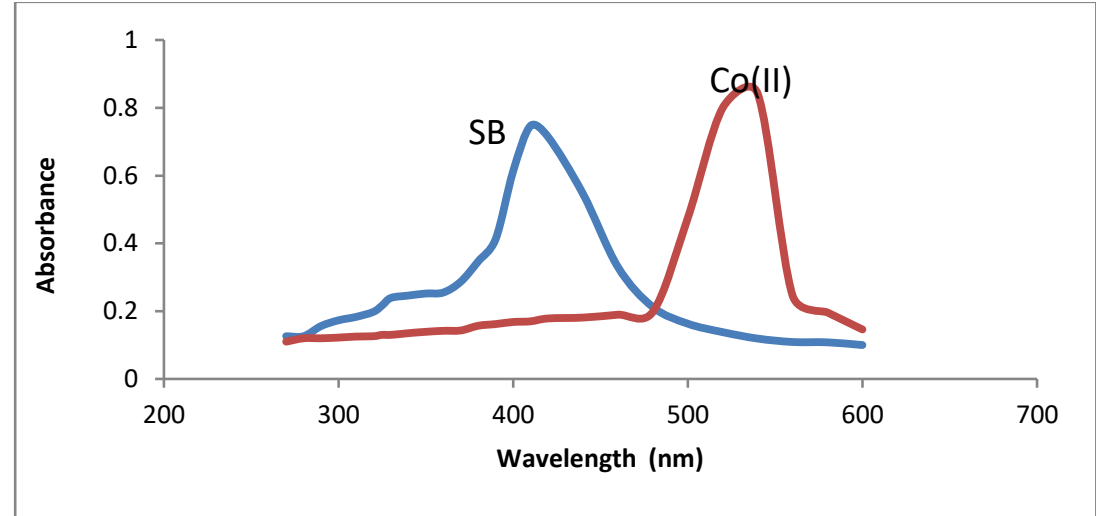

Figure 2a: UV Graph of Schiff base and metal complex

\section{Infrared spectroscopy}

The IR spectra of the SB ligand exhibited bands in the region $1591 \mathrm{~cm}^{-1}$ (Figure $2 \mathrm{~b}$ ) which is due to the stretching frequency of $\mathrm{C}=\mathrm{N}$ group ${ }^{19}$. On complexation, the positional shift have been observed from 1591 to $1550 \mathrm{~cm}^{-1}$ for the band $\mathrm{C}=\mathrm{N}$ in the complex (Figure $2 \mathrm{c}$ ). The sharp band in the region $1666 \mathrm{~cm}^{-1}$ was assigned for the presence of $\mathrm{C}=\mathrm{O}$ group in the ligand was shifted to lower frequency upon complexation ${ }^{20}$. All the values are shown in table 2.2 .

Table 2: IR result of Schiff base and its complex

\begin{tabular}{|c|c|c|c|c|c|c|}
\hline Ligand/complex & $\mathbf{v}$ & $\mathbf{v}$ & $\mathbf{v}$ & $\mathbf{v}$ & $\mathbf{v}$ & Ligand/complex \\
\hline $\mathbf{L}=(\mathrm{C}=\mathrm{N})$ & $(\mathbf{N H})$ & $(\mathbf{C}=\mathbf{O})$ & $(\mathbf{M}-\mathbf{N})$ & $(\mathbf{M}-\mathbf{O})$ & \\
\hline$\left[\mathrm{Co}(\mathrm{L}) \mathrm{Cl}_{2} \mathrm{H}_{2} \mathrm{O}\right.$ & 1550 & - & - & 511 & 420 & [Co(L) $\mathrm{Cl}_{2} \mathrm{H}_{2} \mathrm{O}$ \\
\hline
\end{tabular}




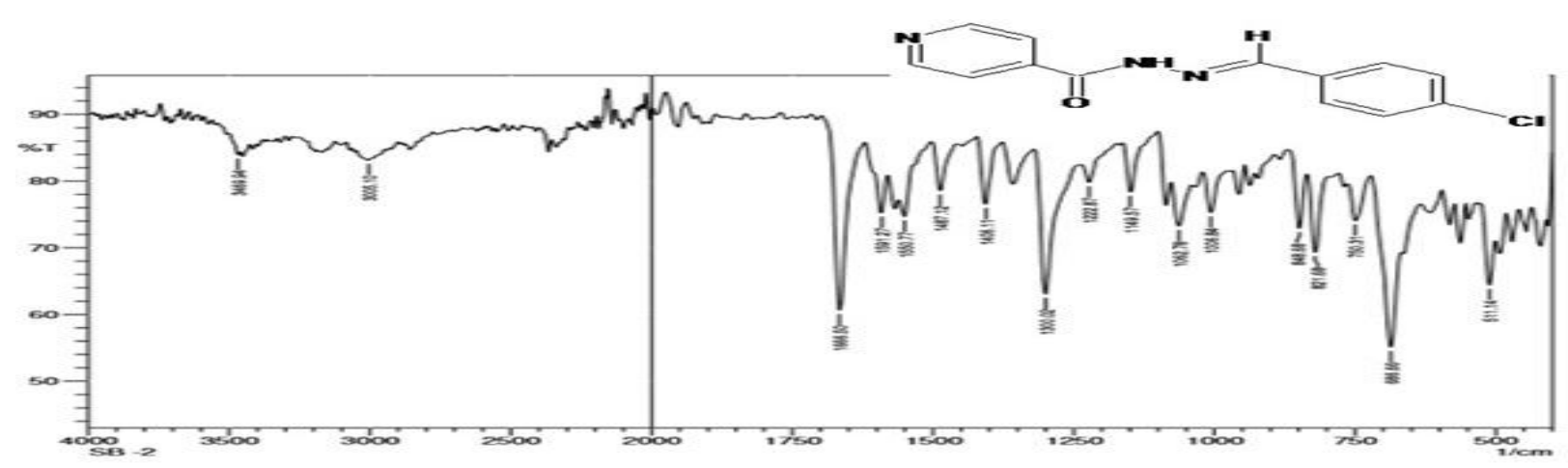

Figure 2b: IR Spectra of Schiff base

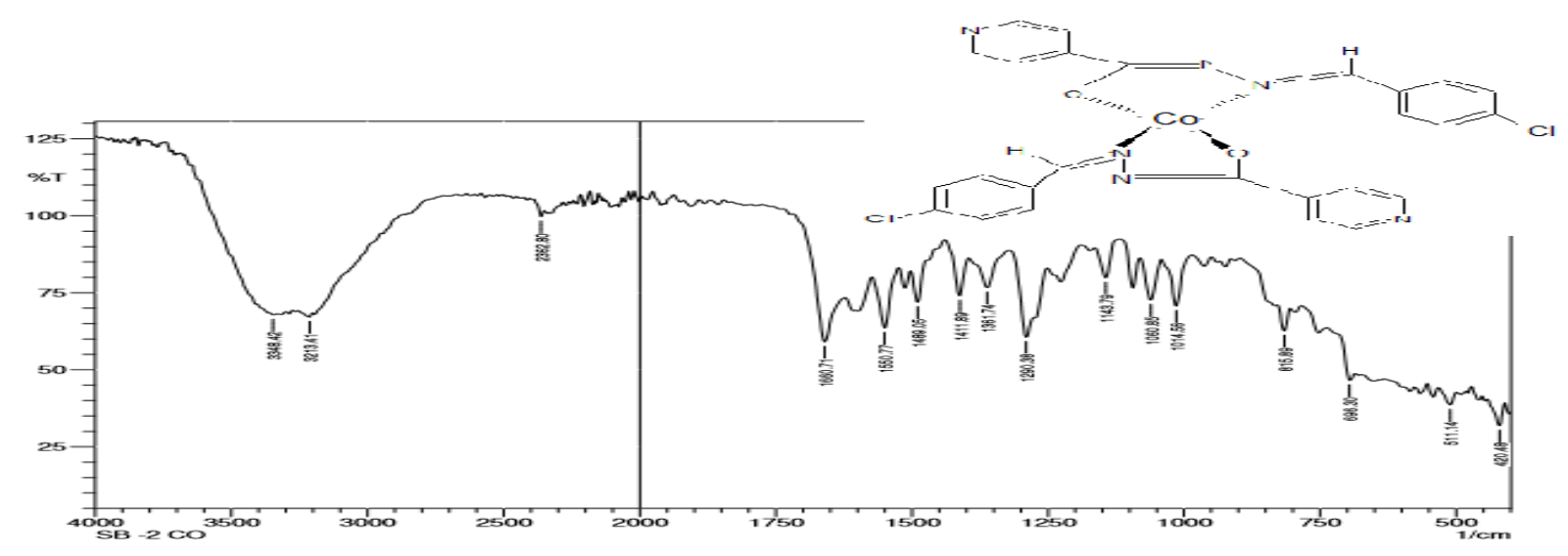

2c: IR Spectra of complex

\section{Antibacterial activity}

The synthesized ligand and Co(II) complex was screened for antibacterial activity against Gram positive bacteria Staphylococcus aureus and Gram-negative bacteria Escherichia coli by using Broth Dilution Method. It is noticed that metal complex shows better inhibitory activity than SB due to the enhanced biochemical potential of bioactive organic species upon Chelation ${ }^{21}$. The higher activity of the metal complex may be due to the effect of metal ions on the normal cell membrane. According to
Tweedy's chelation theory ${ }^{22}$, complexation results in the overlapping of ligand orbital with the metal orbitals and partial sharing of positive charge of metal ion with donor groups of the ligand which reduces the polarity of the metal orbitals $\mathrm{s}^{23}$. This enhances the delocalization of the pi electrons over the entire complex ring thereby promoting the lipophilicity of the chelate ${ }^{24}$. Therefore, chelation enhances the lipophilic character of the metal complex. This favours the complex permeation through the lipid layers of the cell membrane of the bacteria.

Table 3: antimicrobial study of SB and complex

\begin{tabular}{|c|c|c|c|c|c|c|c|c|c|c|c|c|}
\hline \multirow{2}{*}{$\begin{array}{c}\text { Compound name } \\
\text { SB }\end{array}$} & \multicolumn{6}{|c|}{ Escherichia coli (Gram negative) } & \multicolumn{6}{|c|}{ Staphylococcus aureus (Gram positive) } \\
\hline & ++ & ++ & +- & +- & - & -- & ++ & ++ & ++ & +- & -- & - - \\
\hline Cobalt complex & ++ & +- & -- & -- & -- & -- & ++ & +- & -- & - - & - - & - - \\
\hline
\end{tabular}

\section{CONCLUSION}

The SB ligand N'-[(4-chlorophenyl) methylidene] pyridine4-carbohydrazide was successfully synthesized and complexed with Co(II) metal ion. The metal complex was characterized by elemental analysis, FT-IR and UV-Visible spectra. The IR spectra of ligand shows that the coordination to Cobalt is via $\mathrm{C}=\mathrm{N}$ and $\mathrm{C}-\mathrm{O}$. On complexation the absorption band was shifted to higher wavelength due to the formation of coloured complex. The proposed structure says the complex has square planar geometry. Synthesized SB and metal complex were screened for its antimicrobial activity. Also, from this study it can be concluded that the antibacterial growth inhibition ability of the synthesized complex increases upon complexation.

Acknowledgments: The authors are thankful to B M S College for Women, Bengaluru for providing the lab facilities to carry out the research work. 


\section{REFERENCES}

1. Raman N, Muthuraj, Ravichandran VS, Kulandaisamy, Synthesis, characterisation and electrochemical behaviour of $\mathrm{Cu}(\mathrm{II}), \mathrm{Co}(\mathrm{II})$, $\mathrm{Ni}$ (II) and $\mathrm{Zn}$ (II) complexes derived from acetylacetone and $\mathrm{p}$ anisidine and their antimicrobial activity, Journal of Chemical Sciences, 115, 2003, 161-167.

2. Chohanand, $\mathrm{ZH}$, Sherazi KA, Synthesis, characterization and role of anions (nitrate, sulphate, oxalate and acetate)in the biological activity of hydrazine derived compounds and their metal chelates, Metal-Based Drugs, 4, 1997, 327-332.

3. Das PK, Panda PN, Behera NK, Synthesis, characterization and antimicrobial Activities of Schiff Base complexes derived from Isoniazid and Diacetyl monoxime, International Journal of Innovative Science, Engineering \& Technology, 3, 2016, 2348-7968.

a. Temitope E, Olalekan P, Ibrahim OS, Synthesis, Characterization, and Antimicrobial Activity of Carboxylate-Bridged Homodinuclear Schiff Base Metal(II) Complexes, The Pacific Journal of Science and Technology, 16, 2016, 65-72.

4. Ommenya FK, Nyawade IEA, Andala IDM, Kinyua, J, Synthesis, characterization and antibacterial activity of Schiff Base, 4-Chloro2-\{(E)-[(4 Fluorophenyl) imino] methyl\}phenol Metal (II) Complexes, Journal of Chemistry, 1, 1864, 118-119.

5. B. S. Sathe BS, Jayachandran E, JagtapVA, Sreenivasa GM, Synthesis and antibacterial, antifungal activity of novel analogs of fluorobenzothiazole Schiff bases, Journal of Chemical and Pharmaceutical Sciences, 3, 2010, 216-217.

6. Sondhi SM, Singh N, Kumar OL, Meijer L, Synthesis, antiinflammatory, analgesic and kinase (CDK-1, CDK-5 and GSK-3) inhibition activity evaluation of benzimidazole/benzoxazole derivatives and some schiff's bases, Bioorganic \& Medicinal Chemistry, 14, 2006, 3758-3765.

7. Mishra RM, Pandey S, Saxena R, Homozygous hemoglobin D with alpha thalassemia: case report The Open Hematology Journal, 2, 2011, 1-4.

8. Ajit K, Pandeya SN, Synthesis and anticonvulsant activity (chemoshock) of schiff and mannich bases of isatin derivatives with 2-amino pyridine (mechanism of action), International Journal of Pharmtech Research, 4, 2012, 590-598.

9. Sherif AA, Eldebss TMA, Synthesis, spectral characterization, solution equilibria, invitro antibacterial and cytotoxic activities of $\mathrm{Cu}(\mathrm{II}), \mathrm{Ni}(\mathrm{II}), \mathrm{Mn}(\mathrm{II}), \mathrm{Co}(\mathrm{II})$ andZn(II) complexes with Schiff base derived from 5-bromosalicylaldehyde and 2aminomethylthiophene, Spectrochimica Acta PartA: Molecular and Biomolecular Spectroscopy, 79, 2011, 1803-1814.

10. Rehder $D$, Biological and medicinal aspects of vanadium, Inorganic Chemistry Communications, 5, 2003, 604-617.
11. Treatment of Tuberculosis Guidelines, WHO, Geneva, 2010, 30.

12. Pyridine and Pyridine Derivatives, Ullmann's Encyclopaedia of Industrial Chemistry, New York, John Wiley \& Sons, 2007.

13. Kriza A, Mitu L, Stanica N, Synthesis and Characterization of Some Tranzition Metals Complexes with Glyoxal bis- Isonicotinoyl Hydrazone, Revista De Chimie, Bucharest, 60, 2005, 555-560.

14. Kurup MRP, Suresh E, Synthesis and crystal structure of cobalt(III) complex with a Schiff base and azide, Journal of Chemical Crystallography, 37, 2006, 31-36

15. Khan S, Bhar K, Roy S, Ramachandran K, Synthesis, structures and molecular properties of two mononuclear Cobalt(III) halide complexes containing a tetradentate N-Donor Schiff Base, Indian Journal of Chemistry, 50, 2011, 1429-1435.

16. Evans N, Mainsah, Sally-Judith E, Mariam AC, George T, et al. Synthesis, characterization and crystal structure of cobalt(II) complex of a Schiff Base derived from Isoniazid and Pyridine-4Carboxaldehyde, Crystal Structure Theory and Applications, 8, 2019, 45-56

17. Harris D, Quantitative Chemical Analysis, 8th ed.), W.H. Freeman and Company; New York, 2002

18. Panda AK, Dash DC, Mishra P, Synthesis and characterization of copper(II), nickel(II) and cobalt(II) with [16] 1, 5,6,8, 9, 13, 14, 16-octaaza-2, 4, 10, 12-tetraoxo-7, 15-dithia-1, 3, 3, 5, 6, 8, 9, 11, 11, $13,14,16-$ dodecahydrocyclohexadecane, Indian Journal of Chemistry(A), 37(A), 1996;: 67-70.

19. Rajib LD, and Rajib KD. Synthesis and structure of mixed metal $\mathrm{Zn}_{3} \mathrm{Ni}_{2}$-complexes of tetradentate Schiff bases, Journal of Indian Chemical Society, 91, 2014, 2165-2172.

20. Naeimi H, Moradian M, Synthesis and characterization of nitroschiff bases derived from 5-nitro-salicylaldehyde and various diamines and their complexes of Co (II), Journal of Coordination Chemistry, 63, 2010, 156-162.

21. Mahajan KN, Singh RV, Synthesis, characterization and antimicrobial studies of $\mathrm{Sb}$ (III) complexes of substituted thioimines, Indian Journal of Chemistry Section A, 46, 2007, 1221-1225.

22. Jesmin MM, Salahuddin MS, Habib MR, Khanam JA, Antimicrobial activity of some schiff bases derived from benzoin, salicylaldehyde, aminophenol and 2,4 dinitrophenyl hydrazine, Mycobiology, 36, 2008, 70-73.

23. Al-Amier AA, Al-Majedy YK, Ibrahim HH, Al-Tamimi AA, Antioxidant, antimicrobial, and theoretical studies of the thiosemicarbazone derivative schiff base 2-(2-imino-1-methylimidazolidin-4ylidene)hydrazinecarbothioamide (IMHC), Organic and Medicinal Chemistry, 2, 2013, 5878-5889.

Source of Support: None declared.

Conflict of Interest: None declared.

For any question relates to this article, please reach us at: editor@globalresearchonline.net

New manuscripts for publication can be submitted at: submit@globalresearchonline.net and submit_ijpsrr@rediffmail.com 